\title{
How Plants inspire Façades. From Plants to Architecture: biomimetic principles for the development of adaptive architectural envelopes
}

\author{
Marlén López, Ramón Rubio, Santiago Martín, Ben Croxford \\ ${ }^{1}$ Department of Construction and Manufacturing Engineering. University of Oviedo \\ ${ }^{2}$ The Bartlett, Faculty of the Built Environment. UCL \\ Marlén López \\ IDEASCAD Research Group. C/ Pedro Puig Adam. Room 6.1.19. \\ Campus de Viesques, 33203 Gijon, SPAIN \\ +34 656181913 \\ email address: arqmarlenlopez@gmail.com
}

Highlights

- From plant adaptations to adaptive architectural envelopes using biomimicry

- Adaptive envelopes that change with time to adapt environmental conditions

- Techniques abstracted from plants that respond to different environmental issues

- Climate and environmental issues that act as green triggers

- Design concept generation with dynamic mechanisms and static strategies

\section{ARTICLE INFO}

\section{Keywords:}

Biomimicry

Adaptive Architectural Envelopes

Energy efficiency

Plant adaptations

Climate adaptations

\begin{abstract}
Façades have an important role in the control of energy waste in buildings, nevertheless most of them are designed to provide static design solutions, wasting large amounts of energy to maintain the internal comfort. However, biological adaptation solutions are complex, multifunctional and highly responsive. This paper proposes a biomimetic research of the relationship that can be developed between Biology and Architecture in order to propose innovative façade design solutions. We focus on plants, because of plants, like buildings, lack of movement and remain subject to a specific location. Nevertheless, plants have adapted to the environment developing special means of interaction with changing external issues.
\end{abstract}

This paper provides a methodology to create a data collection of plant adaptations and a design mapping to guide the transfer from biological principles to architectural resources, as well as two design concept cases, opening new perspectives for new possible technical solutions and showing the potential of plant adaptations to environmental conditions at a specific climate. Further step is the transformation of some design concepts into technical solutions through experiments with new technologies that include multi-material 3D printing or advances in material science.

\section{INTRODUCTION}

"Cities are part of the climate change problem, but they are also a key part of the solution." [1]. Currently cities consume the larger part of global energy and are therefore major contributors of greenhouse gas emissions. Moreover cities have key competencies to act on climate change through their responsibilities over urban sectors such as buildings. So much so latterly European Union has been developing a large number of funding building efficiency programmes for research and innovation trying to problem-solve these issues, such as Horizon 2020 framework. Some of these programmes focus on building retrofitting, or the installation of energy-efficient technologies, especially on façades. Façades have an important role in the regulation and control of energy waste, since the facades act as intermediary filters between external environmental conditions and inside users and functional requirements. Due to this decisive role, in recent years facades, architectural skins or envelopes have been the subject of numerous studies and research, always trying to achieve greater efficiency and performance, in terms of energy, comfort or structure. Adaptation is the evolutionary process whereby an organism becomes better able to live in its habitat or habitats [2]. The building envelope, without distinction between walls and roof, is the interface between exterior environmental factors and the interior demands of the occupants [3]

Nowadays, biology is no longer just a matter for biologists, but it is a new inspiration for technological thinking. Some of these studies have looked at nature as a source of inspiration for subsequent application to architecture. This trend or biomimicry is a discipline that has been developing for some time in other fields, such as engineering or medicine, and it is only in recent years where we begin to see its application to architecture. Systems found in nature offer a large database of strategies and mechanisms that can be implemented in biomimetic designs. This study, differs from most others [4][5], as it is based only on plants and their adaptations and interactions with their environment. 
In this paper, a broad overview of the various plant adaptations are provided. Also several techniques abstracted from plants that respond to different environmental issues (e.g. darkness, light, humidity, rainwater, fire, temperature, freezing, air movement or air quality) are discussed for possible application in adaptive systems for building envelopes that respond to changing environmental conditions. Current work is about the transfer of plant adaptation strategies into technology for innovation. To achieve the objectives of designing an adaptive architectural envelope using lessons from natural systems, the following questions have been proposed:

1. How can lessons from plant systems be utilized to create a envelope that incorporates and functions like nature?

2. Is it possible to generate design concepts for building envelopes that regulate environmental aspects, based on adaptation strategies from plants?

3. Is it possible to obtain greater energy efficiency in the construction of exterior walls in buildings by mimicking nature as opposed to building façades according to the traditional processes?

\section{ADAPTIVE ARCHITECTURAL ENVELOPES}

\subsection{ADAPTATION}

Adaptation is the evolutionary process whereby an organism becomes better able to live in its habitat or habitats [2]

Most of definitions about building envelope establish it as an enclosure, a separation between the interior and exterior environment, that provides the following functions: support, control, finish (aesthetics) and distribution of services. However, we are more interested in the building envelope as an interface and not a separation. Building envelope, without distinction between walls and roof, as the interface between exterior environmental factors and the interior demands of the occupants [3]

The environment is constantly changing and producing new challenges to cope with. Light (solar radiation), temperature, relative humidity, rainwater, wind (air movement), noises and carbon dioxide (air quality) are the basic environmental issues affecting the building. These issues affect significantly occupant comfort demands as well as building performance. Despite the fact that the climatic characteristics of the area are variable parameters, conventional façades are largely static; so, we use large amounts of energy in order to control internal comfort. Great deal of energy is wasted to heat, cool, ventilate or light our buildings between quite well defined limits, while external environmental factors can change considerably, resulting in existing solutions of static building envelope and dynamic building services. Traditionally, the building envelope has been considered as thermal barrier or shield that has to be for example, insulated to prevent heat loss or shaded to control solar gain. This approach limits more efficient solutions, where the building envelope is not considered as a barrier but as a medium. Therefore conventional solutions for façades and roofs are not designed for optimum adaptation to contextual issues and needs. As opposed to our buildings, which remain inert, living objects respond to the environment and they are able to adapt to the changing weather conditions [6]. We are interested in biological solutions to adaptation because of they are often complex, multi-functional and highly responsive.

An adaptive architectural envelope is one that responds to changing environmental conditions both interior and exterior while managing the indoor environment. Adaptive architectural envelopes have the ability to change with time through adaptation strategies to anticipate exterior environmental variations as well as interior activities and their interactions with inhabitants. We research into adaptive architectural envelopes with two main proposals: contributing to energy-saving for heating, cooling, ventilation or lighting, as well as inducing a positive impact on the indoor environmental quality of buildings. Therefore, the building envelope could be constructed, not with the traditional inert surfaces but with a "living" cladding, which could house a wide range of technologies based on the behaviour of the envelopes found in nature [7]

\subsection{ADVANCES IN ARCHITECTURAL ENVELOPES}

Traditionally external control systems have been looked for in windows and doors, through the utilization of inexpensive and easy to operate manual shading or protection devices, such as exterior louvers, blinds or sunshades. These operable devices can control e.g. solar thermal intrusion and reduce heat gain through windows and other glazed areas [8]. Since the last
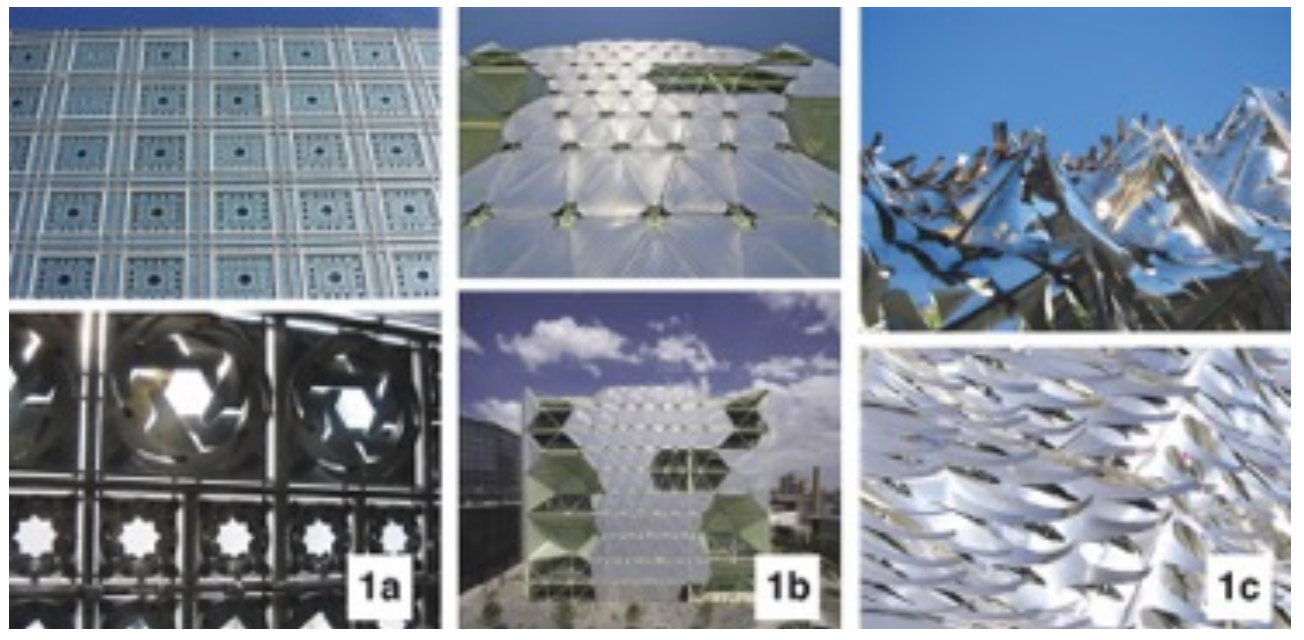

Figure 1. Some examples of dynamic façades from recent years: (a) Arab Institute façade (b) Office Building Media-TIC and (c) Bloom installation details 
century different design proposals for more active and less static façades have gradually emerged, kinetic facades as environmental control systems, capable of responding to different changing environmental aspects. Some of these proposals have not passed the theoretical level, such as the concept developed in 1930 by Le Corbusier " the house of exact breathing", because of the lack of technology at that time for such a futuristic idea. The Arab Institute (Fig. 1a) completed in 1987, by Jean Nouvel, was one of the first to employ an active façade based on automatic response to environmental sensors. 25,000 solar cells, similar to a camera lens, are controlled via a computer to moderate light levels on the south facade. [9]

In recent years concepts such as interactive architecture, architectural kinetics and dynamic structures are increasingly common. Office Building Media-TIC (Fig. 1b) by Enric Ruiz Geli (Cloud 9) and Bloom (Fig. 1c) by Doris Kim Sung are noted examples of these advances in adaptive architectural envelopes. In the first one, the building interacts with its environment through the ETFE skin, arranged in three inflatable layers in the form of a vertical cloud that filters solar radiation. The system of inflation is activated automatically by way of a network of temperature sensors [10][11]. And the second one is a sun-tracking instrument indexing time and temperature, Bloom stitches together material experimentation, structural innovation, and computational form pattern making into an environmentally responsive installation [12][13].

\subsection{BIOMIMICRY}

The terms biomimicry and biomimetics come from the Greek words bios, meaning life, and mimesis, meaning to imitate. Biomimetics is defined as the 'abstraction of good design from nature' [14] or 'mimicking the functional basis of biological forms, processes and systems to produce sustainable solutions' [15].

In recent years other research works have been developed around biomimicry to look into new solutions in architecture. Some of them try carrying out different methodologies for developing new building envelopes based on biomimetic principles. In the images below we present some of the built projects, of envelopes for buildings and their adaptation and interaction with the environment through energy exchanges and improving efficiency. The first one is Flectofin ${ }^{\circledR}$ (Fig. 2a) by ITKE. Inspired by the valvular pollination mechanism in the Strelitzia reginae flower (commonly known as the Bird-OfParadise) flectofin is a hinge-less louver system that is capable of shifting its fin 90 degrees by inducing bending stresses in the spine caused by displacement of a support or change of temperature in the lamina [16][17][18]. The second one is the One Ocean Thematic Pavilion (Fig. 2b) for Yeosu Expo 2012 in Korea, by SOMA, in collaboration with Knippers Helbig Advanced Engineering, for the development of the bionic principle of the kinetic media façade, inspired by the observation and analysis of biological models [18]. And the third case presented is a meteorosensitive pavilion called HygroSkin (Fig. 2c) by Achim Menges in collaboration with Oliver David Krieg and Steffen Reichert. This project uses the responsive capacity of the material itself. The dimensional instability of wood with respect to moisture content is employed to construct a weathersensitive architectural skin that autonomously opens and closes in response to weather changes but neither requires the supply of operational energy nor any kind of mechanical or electronic control [20][21][22].

Besides these projects we could mention some academic research works of reference for us, such as "Towards the living envelope" [4] or "Architecture follows nature" [5] where several biological principles are studied for innovative design in building envelopes. Unlike these studies, this research is based only on plants and their strategies of adaptation to different climates, because of plants like buildings, lack of movement and remain subject to a specific location, so they have to resist weather conditions that affect them at all times. This concept will be more detailed in the following sections.

\section{ADAPTATION SOLUTIONS IN PLANTS}

This paper only focuses on those adaptations to environment shown by plants. Plants, because of their immobility have developed special means of protection against changing environmental issues (e.g. darkness, light, humidity, rainwater, fire, temperature, freezing, air movement or air quality). These adaptations develop over time and generations as a response to the ever changing environment. Evolution and adaptation of
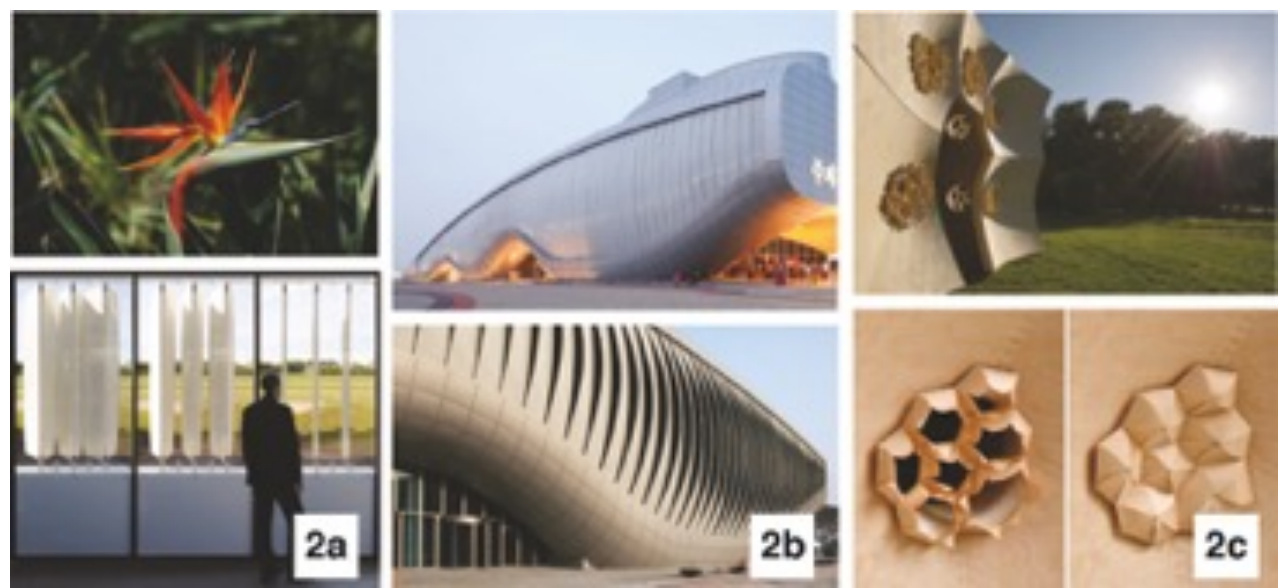

Figure 2. Examples of biomimetic projects for adaptive architectural envelopes: (a) Flectofin ${ }^{\circledR}$ (b) One Ocean Thematic Pavilion (c) HygroSkin 

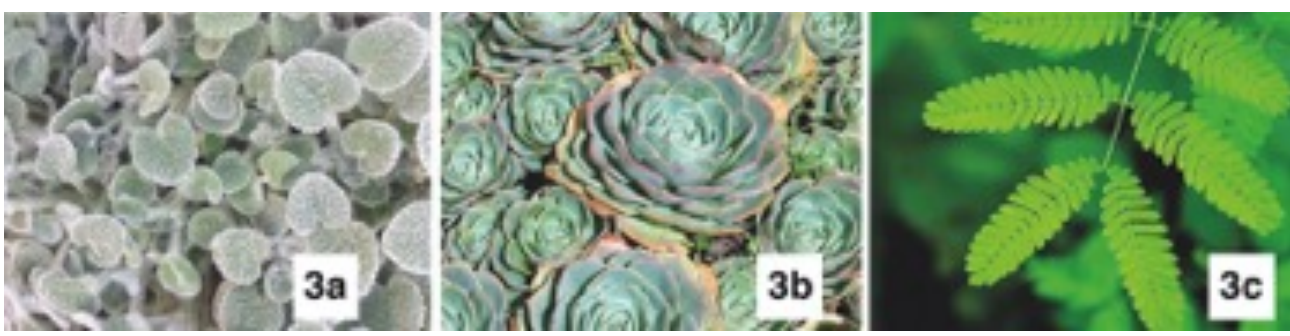

Figure 3. Different types of adaptation solutions (a) Hairy leaves of Gynandriris setifolia (b) Echeveria

Glauca is an example of a CAM plant (c) Leaves of Mimosa Pudica react to contact with a rapid movement

living organisms to their environment occurs in three main ways: morphological, a physiological and behavioural [23]. Following these types of adaptation solutions are explained through plant examples. However in the next section we will develop a second approach in terms of dynamic mechanisms and static strategies, as a part of the design methodology to facilitate the transfer from biology to architecture.

Morphological or structural: relating to an organism's shape, size, pattern or structure dependent on their particular environment, and enables better functionality for survival. An example are the hairy leaves of Gynandriris setifolia (Fig. 3a) These hairs, used to reflect sunlight from their surface, are an adaptation to dry and hot environments.

Physiological or functional: relating to an organism's chemical processes. An organismic or systemic response of an individual to a specific external stimulus in order to maintain homeostasis. Some plants use CAM photosynthesis as an adaptation to arid conditions for increased efficiency in the use of water, and so is typically found in plants growing in arid conditions [24] such as Echeveria Glauca (Fig. 3b)

Behavioural: relating to how an organism acts. The actions organisms take for survival. This type of adaptation is linked to a signal feedback system of signal and response, where behaviour marks an interaction between the organism and its environment. Some leaves close under various stimuli, such as Mimosa Pudica (Fig. 3c), which folds inward as a reaction to contact.

\section{DESIGN METHODOLOGY}

\subsection{DATA COLLECTION}

Analysis of adaptation plants strategies to their environment is the basis of this research. Previously we have seen a first general classification of the three main adaptations of living organisms to their environment through plant examples. However, categorization and organization of the obtained biophysical information is a challenging process and a first approach through a data collection is required in order to be able to apply solutions from nature to architectural solutions. With this classification we try to organize most examples of interest found in different climatic areas. Also, the core of this proposal is the movement resulting in two approaches, being dynamic or static. From now on we consider the ways that plants have adapted in response to challenges as dynamic mechanisms and static strategies. These two main approaches could be further divided into a macro and a micro scale. Within this first level, a second one is defined according to the environmental issues that act as green triggers (i.e. darkness, light, humidity, rainwater, fire, temperature, freezing, air movement or air quality). In summary information organized on a Data Collection uses a classification system to categorize the different ways in which plants adapt and interact with their environment. The data collection (Flg. 4) proposed organizes biological examples by adaptation according to climate type and environmental issues as well as movement approach and main biological principle.

\subsubsection{DYNAMIC MECHANISMS}

Plants respond to external stimuli through movement, called tropisms or nasties, according to whether the motion or response is dependent on the direction or position of the stimulus. We focus on those plants that are responsive plants, those that, exhibit rapid and reactive movements, in a timescale that we can perceive. In this way, we study how plants react to light, temperature or water changes through reactive mechanisms in the macroscopic and microscopic scales. Seeds of many Mesembryanthemums (Fig. 5a), dispersed thanks to a valve mechanism that uses rainwater as a trigger, and leaves of Rhododendron (Fig. 5b) that roll in response to temperature, are two examples of dynamic mechanisms at macro-scale. On the other hand, stomatal movements (Fig. 5c) in response to water,

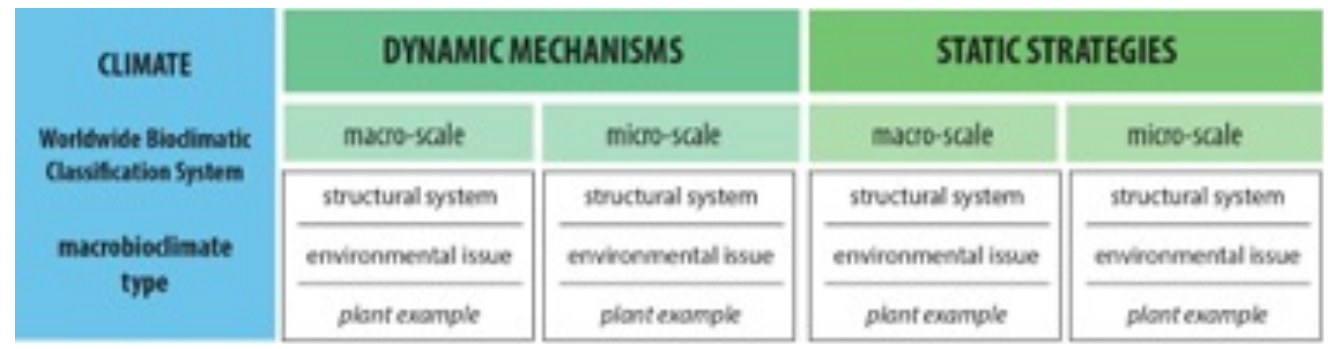

Figure 4. Diagram showing Data Collection proposed 

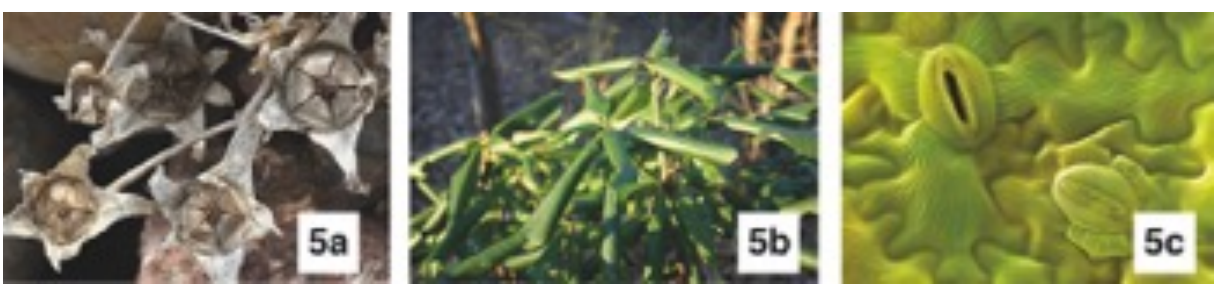

Figure 5. Some dynamic mechanisms: (a) Seeds of many Mesembryanthemums (b) leaves of Rhododendron and (c) stomata on the Lavandula Dentata leaves.
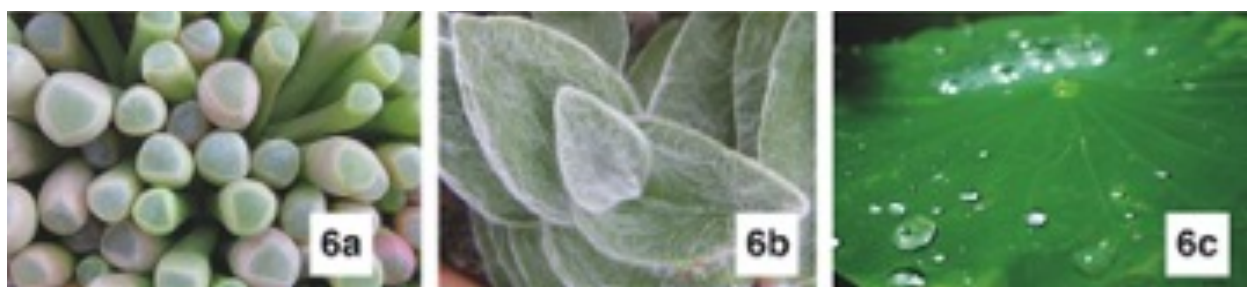

Figure 6. Some static strategies: (a) Transparent leaves of Fenestraria rhopalophylla (b) Hairy surface of Tradescantia sillamontana (c) Superhidrophobicity Lotus leaf

light, temperature and carbon dioxide are an example of dynamic mechanisms at micro-scale.

\subsubsection{STATIC STRATEGIES}

We focus here on the multifunctional properties and surface structures of plants leaves. These highly functional surfaces are the result of millions of years of evolution. Plants from dry and hot environments present different adaptations to the extreme conditions of their habitats. Plant surfaces provide more than one solution for environmental conditions and can include, for example light reflection, superhydrophobic or superhydrophilic surfaces [25][26][27]. Fenestraria rhopalophylla (Fig. 6a) and Tradescantia sillamontana (Fig. 6b) are examples of static strategies at macro-scale, with different solutions for filtering sunlight inside the plant or protecting the plant from direct sunlight and excessive evaporation in dry and hot areas. However the Lotus leaf (Fig. 6c), which is self-cleaning thanks to nanoscale bumps, is a perfect example of a static strategy at the micro-scale.

\subsection{DESIGN CONCEPT GENERATION}

After a data collection to organize information of plants and how they interact with their environment, a biomimetic design methodology is suggested. This methodology leads to concept designs for adaptive architectural envelopes. A mapping (Fig. 7) is proposed to facilitate the transfer between biological
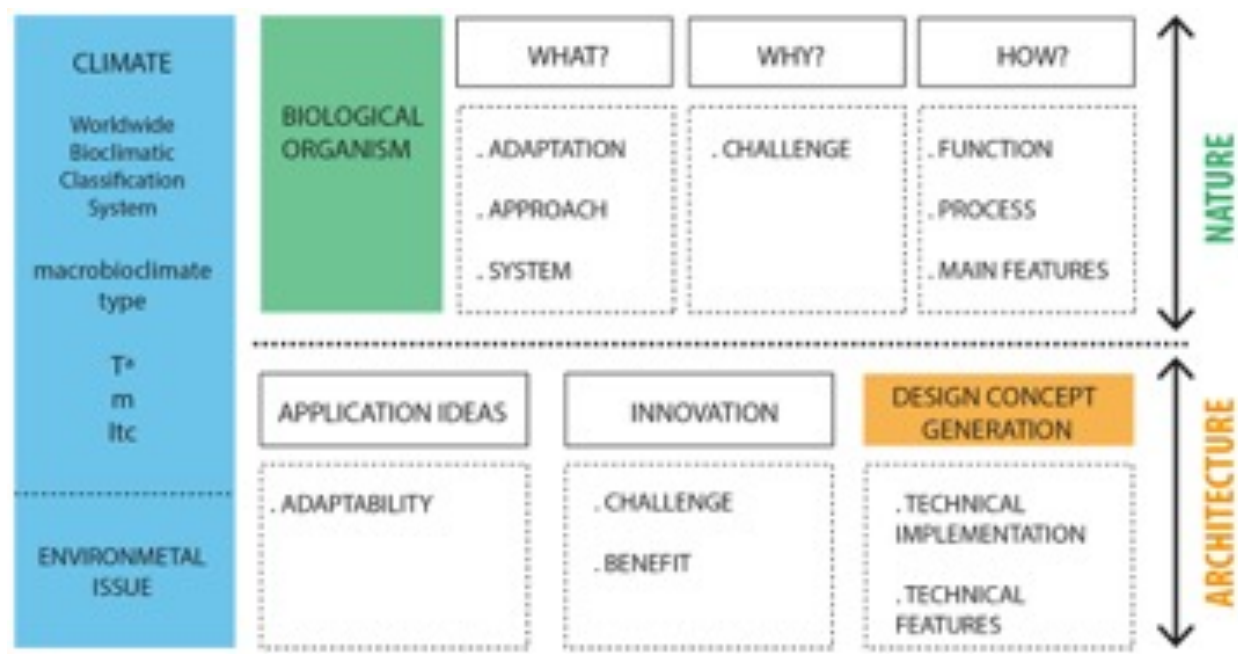

Figure 7. Diagram showing Design Concept Generation proposed 
information and architectural application. There are four different stages during a biomimetic process from biology to engineering: analysis, synthesis, evaluation and implementation [28]. With this mapping the first three stages may be carried out, as a basis for a possible technical implementation in the future. In order to understand how plant principles can be utilized to create adaptive architectural envelopes the proposed methodology is divided into two major stages: the first one is referred to nature and how identify adaptive strategies and mechanisms in plants in different climates. The second one is referred to architecture and how to abstract and transform the selected ideas into innovative solutions for buildings. Stage of Nature is related to more analytic and scientific concepts, and it combines with stage of Architecture that is more deductive and creative. Climate data concern directly both stages, nature and architecture, because of we try to achieve the adaptability in each type of environment.

\subsubsection{CLIMATE}

Bioclimatology or Phytoclimatology is the ecological science dealing with the relations between the climate and the distribution of living species on the Earth. Phytosociology is the science dealing with plant communities, their relationships with the environment and the temporary processes modifying them [23]. The study of all these concepts is part of the research process in which plant communities, and their relations to the environment, and the temporal processes that modify them are analysed. The basis of the success of plants is the ability to compete in their environment. This ability depends mainly on their physiological evolution and adaptation to the environment, so the climate context of the selected plants are described. Several variables are detailed, including temperature, precipitation and humidity. This information is particularly relevant as an introductory element to the biological analysis as well as the architectural proposition.

One of the most important applications of physiological principles refers to the study of the relationships between plants and climate, with physical and physiological environmental factors and the relationships between them. All those factors mean stress to the organisms can affect their distribution. Climatic factors include intensity and periodicity of heat and light, precipitation and relative humidity, as well as wind or the periodicity and duration of the seasons. This leads us to the analysis of the distribution of plants in different geographical territories as climatic factors, or in other words Bioclimatology. Taking as a reference the Worldwide Bioclimatic Classification System [29], we focus on Europe, where we can see four of the five broad macro-bioclimate types defined: Mediterranean, Temperate, Boreal and Polar.

Climate context of the plant species is the first information described in mapping of design concept generation. This description includes the macro-blioclimate type and its main features, according to three parameters: $T$ (yearly average temperature in centigrade degrees), $\mathrm{m}$ (average minimum temperature of the coldest month of the year) and Itc (compensated thermicity index). We also define the environmental issue as "green" trigger that leads this adaptation (i.e. darkness, light, humidity, rainwater, fire, temperature, freezing, air movement or air quality). This climate information is the starting point and the key of this research, because of plants have unique strategies for dealing with the climate they exist in , and we try to develop unique adaptation solutions in envelopes on buildings at different locations. Therefore, this climate data is valid both for natural stage of analysis and for architectural stage of application, and it is the main topic of this methodology. We must select one of the biological examples at Temperate macro-bioclimate if we want to apply these adaptation principles into a building located at the same macro-bioclimate.

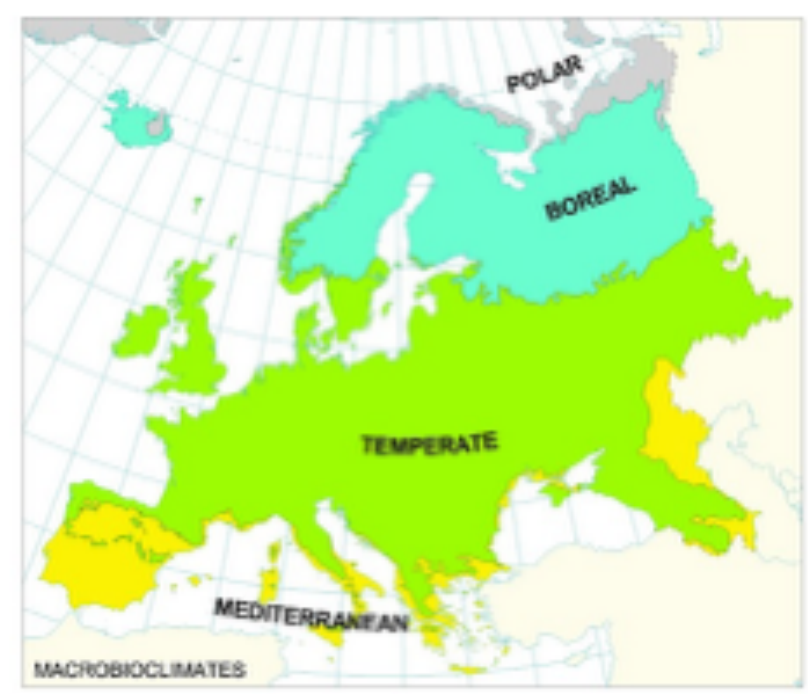

Figure 8. Image of Bioclimatic Map of Europe

\subsubsection{FIRST STAGE: NATURE}

This first stage provides an overview on the explored biological organisms, i.e. plants, and is organized according to three important questions: what is the plant adaptation analysed, why that plant has performed this adaptation and how plant has developed these specific functions.

\section{QUESTION 1: WHAT?}

We look into general description of plant adaptation, through analysis of data such as the type of general adaptation (morphological, physiological or behavioural) or the approach and scale (dynamic mechanism or static strategy in macro or micro scale). Also, structural system is described, e.g. valve mechanisms, reflective structures or absorbing surfaces.

\section{QUESTION 2: WHY?}

Biological challenge is explored to determinate function. What challenge must that plant address to survive at that climate area? We identify a verb that directly define the biological challenge. Why does that plant need to perform this strategy?

\section{QUESTION 3: HOW?}

We study how plants develop specific functions, i.e. how a mediterranean plant manages the capture and storage of water, how is possible to avoid dehydration or survive the great changes of temperature between day and night. To understand these specific behaviors for adaptation and functional specialization, the relationship between structure, morphology 
and function are analyzed. From the scale of microscopic observation and using SEM (scanning electron microscope) micrographs could be useful tools for the static approaches. Most important concepts described are function, process and main feature. Function is necessary to achieve challenge required, thus we extract the functionality of mechanisms or strategies, e.g. opening, reflecting, controlling or absorbing. Function will be determinant of the design concept success. Process describes how this organism has developed these special adaptations, also it provides the understanding why this plant is able to survive on that specific climate. Finally the main feature of the performance is indicated, e.g. hygroscopicity or dense coverage.

\subsubsection{SECOND STAGE: ARCHITECTURE}

Based on the main principles for plant adaptations, in this second stage we are analogously able to abstract and transform these principles into technical solutions and further implementations for adaptive architectural envelopes. This stage is resolved with three important concepts: Application ideas, Innovation and Design concept generation.

\section{CONCEPT 1: Application ideas}

Application ideas suggest a kind of adaptability, i. e. dynamic adaptive envelope or static adaptive envelope. Previously we have seen how plant adaptations could be organised according to movement and environmental issues in a data collection. Adaptive architectural envelopes can be divided in two approaches as well: the adaptive behaviour could be based on a movement through dynamic mechanisms or material properties through static strategies. The first type of adaptability in adaptive architectural envelopes implies that a certain kind of observable motion is present, resulting in changes in the envelope configuration via moving parts. Examples of types of motion could be: folding, sliding, expanding, creasing, hinging, rolling, inflating, fanning, rotating or curling. In the other type of adaptive architectural envelopes, changes directly affect the internal structure of a material, also adaptability is manifested via changes in specific properties, such as light reflection or absorption properties, or through the exchange of energy from one form to another.

\section{CONCEPT 2: Innovation}

Some innovation ideas are proposed according design challenges and benefits. Why is this solution design better than those existing? This concept tries to show the benefit or advantages of the biomimetic design methodology, for the design of new adaptive architectural envelopes or for refurbishment applications, compared to a standard or traditional building system in terms of energy efficiency.

\section{CONCEPT 3: Design concept generation}

Design concept generation comes from biological observation, so it involves an abstraction of biological terms to constructive terms. The resulting design concept is not a direct translation from particular adaptation plant, but is inspired by studying its function, morphology and nature. Innovative forms will emerge from this explorative process. Preliminary drawings and constructive details, based on analysis of adaptation plant according to previous questions, are made in order to formulate possible technical implementation. Technical application is a definition of the constructive or implementation idea and is determined by the technical features of motion, geometry, patterns or material properties.

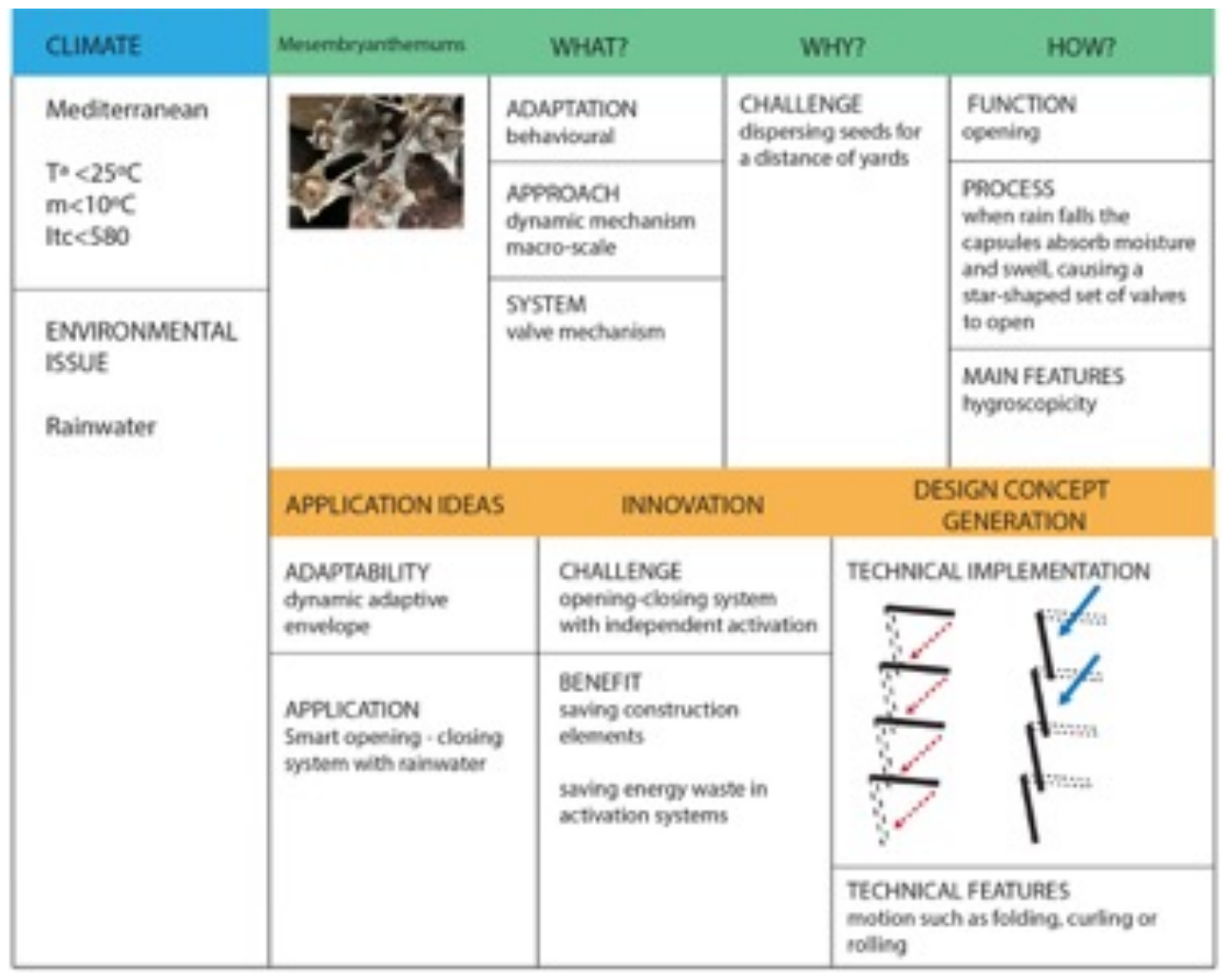

Figure 9. Diagram of a dynamic design case for smart opening-closing envelopes by rainwater 


\section{DESIGN CASES}

Two different theoretical design cases based on solutions adapted by plant adaptations are presented.

The first design case (Fig. 9) shows the possible realization of an adaptive architectural envelope from a dynamic approach. Based on the seeds of Mesembryanthemums, that are launched from their capsules for dispersal thanks to a valve mechanism that uses rainwater as a trigger, a smart opening-closing system is suggested for new buildings. These plants are from Mediterranean climate and when rain falls the seed capsules absorb moisture and swell, causing a star-shaped set of valves to open. A new adaptive water envelope is proposed by the material behaviour which uses rainwater as a trigger to open or close itself. This kind of solution is a dynamic mechanism which architectural benefit consists in saving or reducing the number of construction elements in windows, as well as allowing an independent and autonomous activation to adapt changing environmental conditions in buildings located at rainy cities.

The second design case (Fig.10) shows the possible realization of a responsive and adaptive temperature system. It has an advantage of adapting to changing temperature levels passively. Basing on some plants at Mediterranean climate, such as Salvia officinalis and Kalanchoe pumila, a reflective envelope over existing façades is suggested for refurbishment. These plants have developed reflective structures for protect themselves against excessive sunlight and temperature, by strategies of three dimensional waxes or dense coverage with air-filled hairs.
This kind of solution is a static approach which architectural benefit consists in saving energy waste in cooling systems in buildings located at dry and hot cities, besides helping to reduce urban heat island.

\section{CONCLUSIONS}

This paper focuses on those adaptations to environment shown by plants at different macro-bioclimates. With this paper authors provide a broad overview of the various plant adaptations to different climate conditions found in nature to apply in specific solutions for adaptive architectural envelopes design. Stages of analysis, synthesis and evaluation from biology to engineering have been carried out, for the purpose of establishing design strategies for their possible development and technical implementation in the future. Climate information is the starting point and the key of this research, because of plants have unique strategies for dealing with the climate they exist in, and we try to develop unique adaptation solutions in envelopes on buildings at different locations.

Answering some introductory questions we can support that is possible to generate design concepts for building envelopes that regulate environmental aspects, based on adaptation strategies from plants. We have carried out a mapping in order to understand how lessons from plant systems be utilized to create a envelope that incorporates and functions like nature. According our methodology several steps guide the transfer from biological principles to architectural resources. In the example part, the mapping methodology was applied to

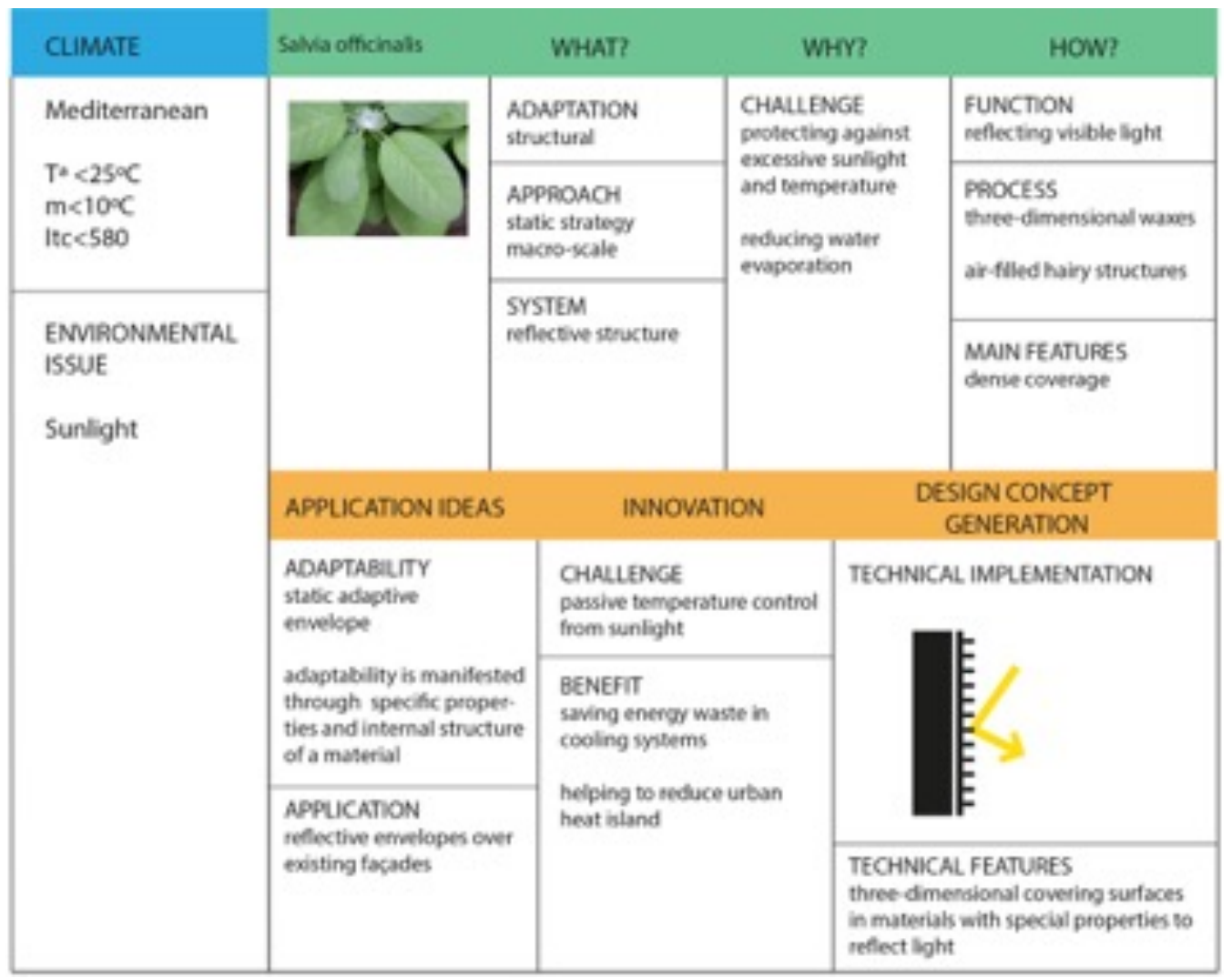

Figure 10. Diagram of a static design case for reflective envelopes in dry and hot environments 
generate two design concepts, a dynamic mechanism for smart opening-closing envelopes by rainwater and a static strategy of a reflective envelope over existing façades. These design cases involve a specific study of plant adaptations to rainy or dry and hot environments to provide a new ways to save energy reducing the number of construction elements in new buildings located at rainy climates or saving waste in cooling systems in old buildings in dry and hot cities.

Regarding whether it is possible to obtain greater energy efficiency in the construction of exterior walls in buildings by mimicking nature as opposed to building façades according to the traditional processes, this work provides several mechanisms and strategies for the design challenge. However the transformation of these into technical solutions for adaptive architectural envelopes requires a large number of studies and experiments with new technologies that include multi-material 3D printing, advances in material science and new capabilities in simulation software.

In summary, the methodology to create a data collection of plant adaptations and the design mapping from plants to architecture, open new perspectives for new possible technical solutions and showing the potential of plant adaptations to environmental conditions at a specific climate to develop adaptive architectural envelopes at the same climate.

\section{ACKNOWLEDGEMENTS}

The authors would like to acknowledge the valuable comments and discussions provided by Professor Julian Vincent (University of Bath), by horticulturist Carlos Magdalena (KEW Royal Botanic Gardens, London) and horticurator Álvaro Bueno (Jardín Botánico Atlántico, Gijón)

\section{REFERENCES}

[1] Kamal-Chaoui, L. \& Robert A., Competitive Cities and Climate Change, OECD Regional Development Working Papers $\mathrm{N}^{\circ} 2,2009$, OECD publishing.

[2] Dobzhansky, T.; Hecht, MK; Steere, WC., On some fundamental concepts of evolutionary biology. Evolutionary biology volume 2(1st ed.). New York: Appleton-Century-Crofts, 1968, pp.1-34.

[3] Del Grosso A.E. \& Basso P., Adaptive building skin structures, IOP Science, Materials and Structures, 2010

[4] Badarnah, L., Towards the LIVING envelope: biomimetics for building envelope adaptation, Delft University of Technology, 2012

[5] Mazzoleni, I., Architecture Follows Nature-Biomimetic Principles for Innovative Design, New York: CRC Press, 2013

[6] Armstrong, R. Living Architecture: How Synthetic Biology Can Remake Our Cities and Reshape Our Lives. TED Books, 2012

[7] Beesley, P., Responsive Architectures: Subtle Technologies, Canada: Riverside Architectural Press, 2006

[8] Leatherbarrow, David \& Mostafavi, Moshen, Surface Architecture, The MIT Press, Cambridge, Massachusetts, 2002

[9] Fortmeyer, R. \& Linn, C., Kinetic Architecture: Design for Active Envelopes, Mulgrave: Images Publishing, 2014

[10] Geli, E. R. \& Rifkin, J., A Green New Deal, From geopolitics to biosphere politics, Barcelona: Actar, 2010

[11] Geli, E.R., Cloud 9. Media-ICT Building, Barcelona: Actar, 2011
[12] Kim Sung, D. Metal that breathes, On-line: TEDxUSC. [Online]. Available: http://www.ted.com/speakers/ doris_kim_sung.html

[13] Kim Sung, D. Bloom. [Online]. Available: http://www.dosuarch.com/bloom.html

[14] Vincent, J., Bogatyreva O., Bogatyrev N., Bowyer, N., and Pahl, K., Biomimetics: its practice and theory, Journal of the Royal Society Interface, 2006, 3, pp. 471-482

[15] Pawlyn, M., Biomimicry in Architecture, London: RIBA Publishing, 2011

[16] Bar-Cohen, Y., Biomimetics: Nature-Based Innovation, New York: CRC Press Taylor \& Francis Group, 2011

[17] Lienhard J., Schleicher S., Poppinga S., Masselter T., Milwich M., Speck T. and Knippers J., Flectofin: a hingeless flapping mechanism inspired by nature. IOP Science, Bioinspiration \& Biomimetics Volume 6 Number 4, 2011

[18] Knippers, J. \& Speck, T., Design and construction principles in nature and architecture. IOP Science, Bioinspiration \& Biomimetics Volume 7, 2012

[19] Schinegger, K., Rutzinger, S., Oberascher, M., Weber, G., One Ocean: Theme pavilion EXPO 2012 Yeosu, Residenz Verlag, 2012

[20] Menges A., Biomimetic design processes in architecture: morphogenetic and evolutionary computational design. IOP Science, Bioinspiration \& Biomimetics Volume 7, 2012

[21] Menges, A., HygroScope - Meteorosensitive Morphology, in Gattegno, N., Price, B. (Eds.), Project Catalogue of the 32nd Annual Conference of the Association for Computer Aided Design in Architecture (ACADIA), San Francisco, 2012, pp. 21-24

[22] Menges, A., Material Computation - Higher Integration in Morphogenetic Design, Architectural Design, Vol. 82, London: Wiley Academy, 2012

[23] Azcón-Bieto, J. \& Talón, M., Fundamentos de fisiología vegetal, Barcelona: McGraw-Hill Interamericana, 2000

[24] Ezcurra, E., Natural History and Evolution of the World's Deserts, Global Deserts Outlook, United Nations Environment Programme, 2006, pp. 1-27

[25] Koch, K., Bhushan, B., and Barthlott, W., Multifunctional surface structures of plants: An inspiration for biomimetics. Progress in Materials Science, 2009, 54, pp. 137-178.

[26] Bhushan, B., Biomimetics: lessons from nature- an overview. Philosophical Transactions of the Royal Society, 2009, 367, pp. 1445-1486.

[27] Gibson, L., The hierarchical structure and mechanics of plant materials. Journal of the Royal Society Interface, 2012, Published online 8 August 2012

[28] Speck, T., Process sequences in biomimetic research. C.A. Brebbia, Design and Nature IV, Southampton: WIT Press, 2008, pp. 3-11

[29] Rivas-Martínez, S., 2004, Worldwide Bioclimatic Classification System, [Online]. Available: http:// www.globalbioclimatics.org 